et al., p. 24). Models can also be tested against past and present scenarios (van Oldenborgh, p. 26; Mudelsee and Girardin, p. 28), which again helps to improve climate predictability.

\section{Format and availability of data}

For a data-model comparison, the proxyreconstruction data needs first to be combined into one large data set with wide temporal and spatial coverage. This requires detailed information on sampling methods, age models and representativeness of proxy data. Fundamental to the continuation of the model-data comparison effort is the availability of and accessibility to data sets of proxy reconstructions and model output (Dittert et al., p. 30). Many recent data-modeling efforts have utilized proxy data sets made available in data archives.

\section{Scientific education-bridging the gaps between disciplines}

Earth System science is traditionally split into various disciplines and sub-disciplines. Overall, the diversity of expertise provides a solid base for interdisciplinary research. However, to gain holistic insights into the Earth System requires the integration of observations, paleoclimate data and climate modeling. These different approaches of Earth System science are rooted in the different disciplines (geology, physics, meteorology, oceanography, etc.), which cut across a broad range of timescales. It is therefore necessary to link these disciplines at a relatively early stage in $\mathrm{MSc} / \mathrm{PhD}$ programs. The linking of data and modeling would enable graduate students from a variety of disciplines to cooperate and exchange views on the common theme of Earth System science, and lead to a better understanding of local processes within a global context.

Computational and conceptual models of the Earth System provide the ability to investigate different scenarios in biogeochemistry, such as the carbon cycle, the structure of marine sediments, and isotope distribution in climate components. Statistical analysis further provides a synthesis, comparison and interpretation of paleoclimate and simulated data. Training and education, particularly in time-series analysis, data exploration, process understanding and model interpretation, should all be key components of future education.

\title{
Northern hemisphere atmospheric blocking in ice core accumulation records from northern Greenland
}

Norel Rimbu, G. Lohmann and K. Grosfeld

Alfred Wegener Institute for Polar and Marine Research, Bremerhaven, Germany; Norel.Rimbu@awi.de

Atmospheric blocking is a large-scale, midlatitude atmospheric phenomenon often associated with persistent quasi-stationary, synoptic-scale, high-pressure systems. The formation, maintenance and collapse of atmospheric blocking cause large-scale circulation anomalies and strongly impact weather patterns. Therefore, blocking regimes constitute a significant climatological feature.

Northern hemisphere blocking shows important variability at different timescales. Blocking frequencies have shown a downward (upward) trend over Atlantic and European (west Pacific) sectors. Su- perimposed on these linear trends, blocking frequencies show significant interannual and decadal variation (Barriopedro et al., 2006). However, in these studies, the blocking variability was derived over the relatively short time period covered by observational data with daily resolution. Here, we present the first attempt to directly relate interannual and decadal variability of several high-resolution snow accumulation records from northern Greenland with northern hemisphere atmospheric blocking. First, we investigate the relationship between atmospheric blocking and accumulation variability dur- ing the period covered by both accumulation and high-resolution (daily) observational data. Based on this relationship, we then discuss the blocking variability over the last $400 \mathrm{yr}$ based only on the accumulation variability.

As an example of blocking circulation, we present in Figure 1a the 500-hPa geopotential height (shaded) and horizontal wind (vectors) during the mature phase (3 February 1975) of the blocking event that occurred in the North Atlantic sector from 28 January to 9 February 1975 (Diao et al., 2006). It can be seen that large-scale westerly flow, which is strongly blocked

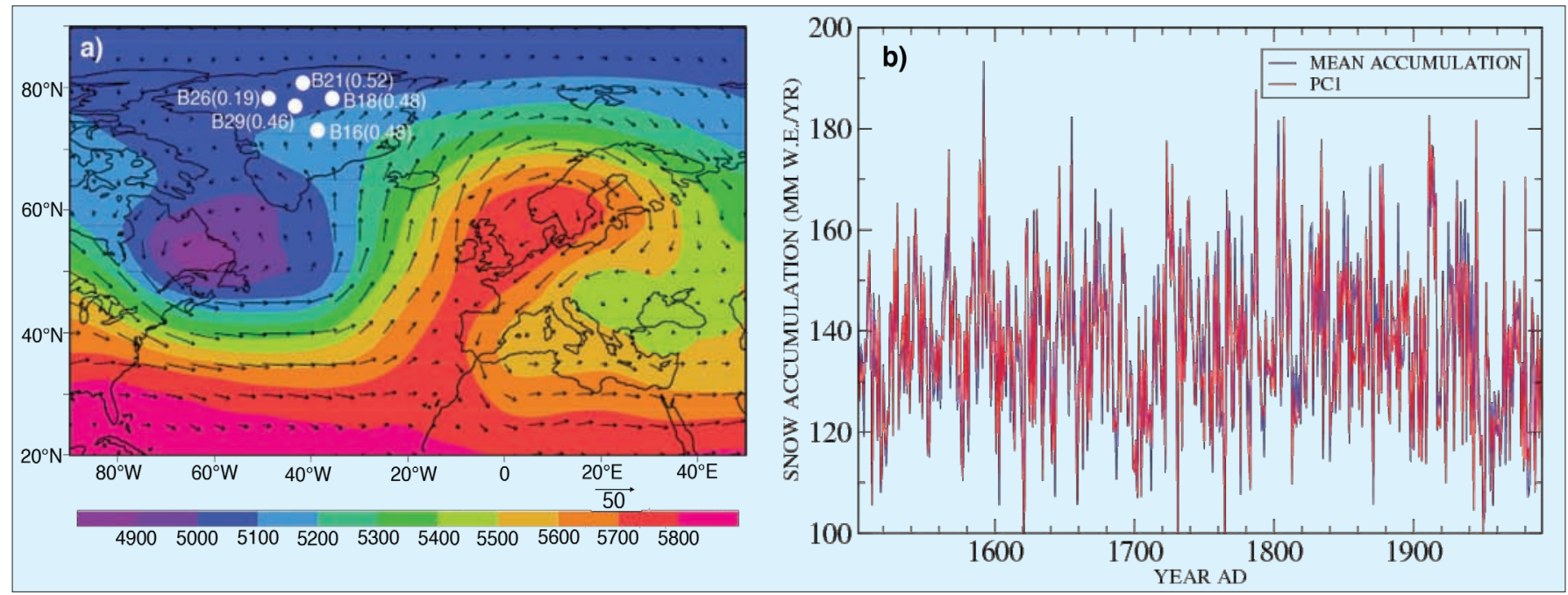

Figure 1: a) The 500-hPa geopotential height (shaded; $m$ ) and horizontal wind (vector; $\mathrm{m} / \mathrm{s}$ ) during the mature stage (3 February 1975 ) of the $28 \mathrm{January} \mathrm{to} 9$ February 1975 blocking event that occurred in the North Atlantic region. Location of core sites (filled white circles) and EOF1 values of snow accumulation records from Greenland are also indicated. $\boldsymbol{b})$ The corresponding time coefficients (PC1) and the mean snow accumulation of the five records represented in a). The PC1 was scaled to have the same mean and variance as the mean accumulation time series ( $\mathrm{mm}$ w.e./yr $=\mathrm{mm}$ water equivalent per year). 
over the northeast Atlantic, influences the Greenland region.

The Alfred Wegener Institute for Polar and Marine Research (AWI) in Bremerhaven, Germany performed a North Greenland Traverse (NGT) between 1993 and 1995 (Schwager, 2000). As a proxy for the blocking variability, we analyzed the yearly snow accumulation time series from five ice cores drilled during the NGT (Fig. 1a): B16 $\left(73.9^{\circ} \mathrm{N}, 37.6^{\circ} \mathrm{W}\right.$; Miller and Schwager, 2004$), \mathrm{B} 18\left(76.6^{\circ} \mathrm{N}, 36.4^{\circ} \mathrm{W}\right.$; Miller and Schwager, 2000a), B21 (80.4 ${ }^{\circ} \mathrm{N}$, $41.1^{\circ} \mathrm{W}$; Miller and Schwager, 2000b), B26 $\left(77.3^{\circ} \mathrm{N}, 49.2^{\circ} \mathrm{W}\right.$; Miller and Schwager, $2000 \mathrm{c})$ and $\mathrm{B} 29\left(76.0^{\circ} \mathrm{N}, 43.5^{\circ} \mathrm{W}\right.$; Miller and Schwager, 2000d). These shallow ice cores reach depths up to $150 \mathrm{~m}$. Mean accumulation rates vary between 104 and 179 $\mathrm{mm}$ water equivalent/yr. The period covered by all five annual resolution records is 1502 to 1992 (or 491 years). These accumulation records are available through the PANGAEA online environmental database (www.pangaea.de).

Accumulation records from Greenland are affected by both meteorological and glaciological noise (Crüger et al., 2004). To filter out this noise and to obtain the dominant patterns of accumulation variability, an Empirical Orthogonal Function (EOF) is applied to normalized accumulation anomalies over the entire 1502 to 1992 period. The first EOF (Fig. 1a), which describes about $24 \%$ of variance, captures in-phase variability of all accumulation records. Its associated time coefficients (PC1) show variations very similar to the mean accumulation of the five records (Fig. 1b).

Since blocking heights affect the middle and upper troposphere, the 500 $\mathrm{hPa}$ geopotential anomaly field is widely used to identify blocking events. A popular algorithm to identify blocking events in this field, also used in our study, was developed by Tibaldi and Molteni (1990). For each longitude, the northern (southern) meridional $500 \mathrm{hPa}$ geopotential height gradients are calculated between three base latitudes, $55^{\circ} \mathrm{N}, 60^{\circ} \mathrm{N}$ and $65^{\circ} \mathrm{N}$ and the corresponding $20^{\circ} \mathrm{N}(\mathrm{S})$ latitudes. A given longitude is defined as blocked at a specific instant in time if at least one gradient between the base and southern latitudes is greater than zero, and at least one gradient between northern latitudes and the corresponding basic latitudes is smaller than $-10 \mathrm{~m} /$ degree latitude (Tibaldi and Molteni, 1990). The frequency of blocking (with neither time persistence or spatial criteria yet imposed) at a certain longitude is defined as the ratio between the number of days when that longitude

a)
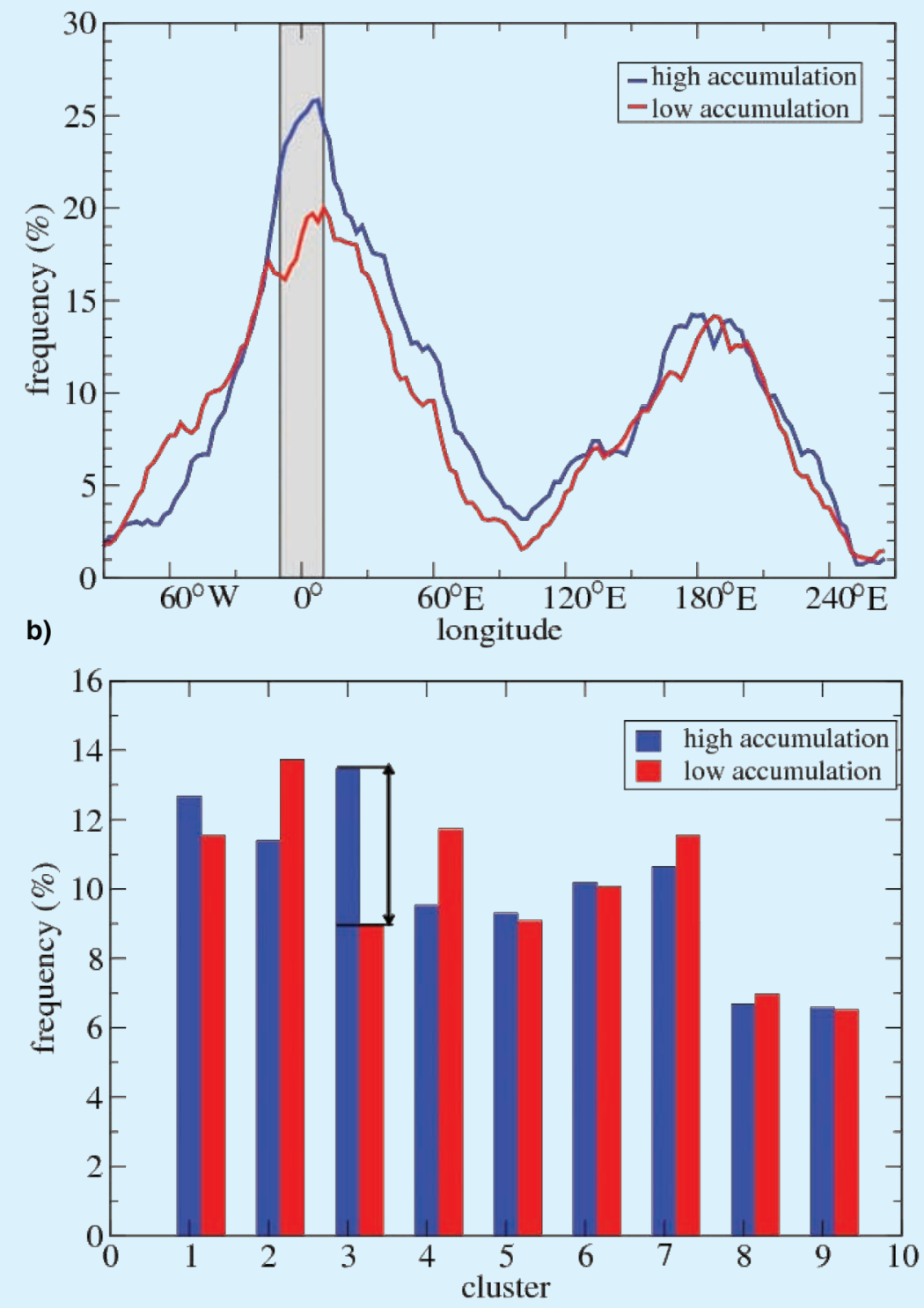

Figure 2: a) Blocking-like frequency as a function of longitude for years of high and low snow accumulation on Greenland during the 1948-1992 period. Shaded area outlines the $5^{\circ} \mathrm{W}-5^{\circ} \mathrm{E}$ area discussed in the text. $\left.\boldsymbol{b}\right)$ Frequency of daily atmospheric patterns during high and low accumulation years during the period 1850-1992 grouped in 9 clusters according to Philipp et al. (2007). The arrow indicates the difference between frequency of cluster 3 for high and low accumulation years.

was blocked to the total number of days of the analyzed period.

The frequency of blocking events during high accumulation years (PC1 higher than 0.75 standard deviation) is significantly higher in the Atlantic-European sector $\left(20^{\circ} \mathrm{W}-100^{\circ} \mathrm{E}\right)$ than the corresponding frequency during low accumulation years (PC1 lower than -0.75 standard deviation). A reverse situation is found for the sector $80^{\circ} \mathrm{W}-20^{\circ} \mathrm{W}$ (Fig. 2a). No significant differences between the frequencies of blocking events during high and low accumulation years were detected outside the Atlantic and European sectors (Rimbu et al., 2007). A cluster analysis of a daily-reconstructed atmospheric circulation since 1850 revealed that winter atmospheric circulation in the Atlantic-European region is optimally represented by 9 clusters (Philipp et al., 2007). To better assess the relationship between the snow accumulation variability on Greenland and Atlantic-European atmospheric circulation, we compared the frequency of these clusters during high and low accumulation years for the period 1850-1992 (Fig. 2b). Significantly higher frequency of cluster 3 is recorded during high relative to low accumulation years. Cluster 3 represents a blocking high centered near the UK (Philipp et al., 2007).

A blocking-like circulation is associated with a blocking event if it is persistent in time and extends over several longitudes. The typical duration of blocking episodes varies between 5 and 30 days (Tibaldi and Molteni, 1990). Based on the frequency distribution of blocking-like circulation states, as represented in Figure $2 \mathrm{a}$, we define a blocking index as the num- 
ber of days in a winter when in sector $5^{\circ} \mathrm{W}$ $5^{\circ} \mathrm{E}$ (Fig. 2a, shaded region) at least three consecutive longitudes are blocked for at least four consecutive days. The blocking index is significantly correlated with accumulation PC1 over the period 1948-1992. This result is confirmed by a composite analysis. It reveals that this sector was blocked on average 13.6 days per winter during high accumulation years, which is significantly more frequent than the 8.6 days per winter during low accumulation years.

To identify the physical mechanism responsible for the relationship between blocking activity and the dominant pattern of accumulation variability, we investigated the moisture transport (Peixoto and Oort, 1992) in the Atlantic European region during years characterized by high and low values of the above-defined blocking index. The axis of maximum moisture transport, defined as vertically integrated water vapor transport (vectors), shifts to a more northeast-directed orientation across the Atlantic and extends northward to Greenland during years of high blocking index values (Fig. 3a) relative to the times of low blocking index (Fig. 3b). A significant reduction in the magnitude of atmospheric moisture transport (contour lines) over Greenland during periods of less frequent blocking relative to periods of frequent blocking is also evident.

We have shown that over periods covered by observed and reconstructed daily
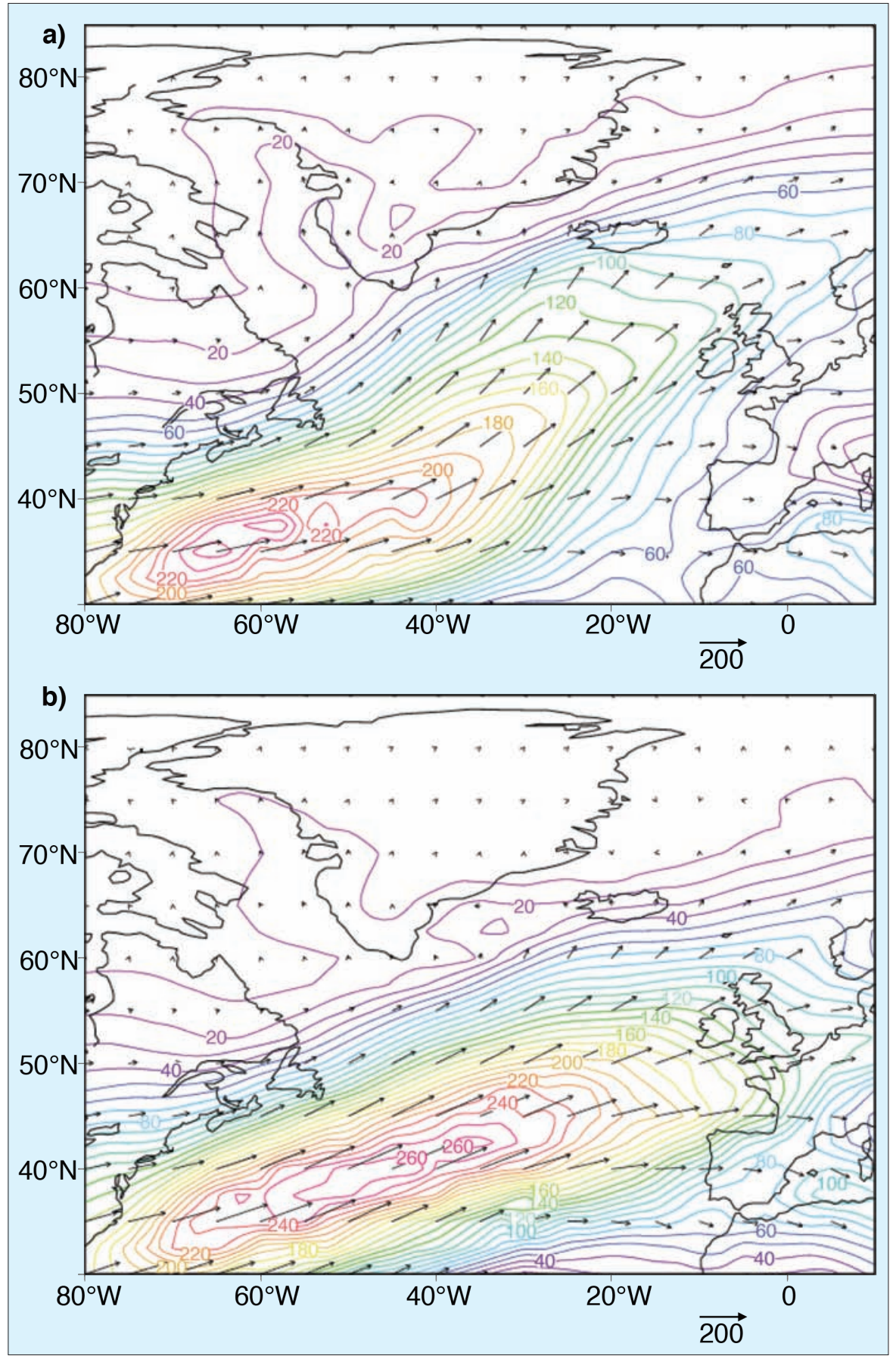

Figure 3: Water vapor transport (vector) during a) high and b) low values of blocking index (see text for definition). The magnitude of the water vapor transport ( $\mathrm{kg} / \mathrm{ms}$ ) is indicated by both contour lines and length of vectors.

atmospheric circulation data, high accumulation in our Greenland ice cores is associated with high blocking frequency in the Atlantic-European region. Assuming that this relationship is stable in time, the periods of relatively high (low) accumulation during the last 400 years are characterized by high (low) blocking activity in the Euro-Atlantic region. We detected significant peaks at bi-decadal ( 20 yr) and multi-decadal $(\sim 70 \mathrm{yr})$ timescales in the PC1 of accumulation records, which may also characterize the blocking activity in the Atlantic region. Our analysis should be extended to other proxy data, as well as to climate model experiments, for a better understanding of blocking variability during past periods.

\section{References}

Diao, Y., Li, J. and Luo, D., 2006: A new blocking index and its application: blocking action in the Northern Hemisphere, Journal of Climatology, 19: 4819-4839.

Philipp, A., Della-Marta, P.M., Wanner, H., Fereday, D.R., Jones, P.D. and Moberg, A., 2007: Long-term variability of daily North AtlanticEuropean pressure patterns since 1850 classified by simulated annealing clustering, Journal of Climate, 20: 4065-4095.

Rimbu, N., Lohmann, G. and Grosfeld, K., 2007: Northern Hemisphere atmospheric blocking in ice core accumulation records from northern Greenland, Geophysical Research Letters, 34: L09704, doi:10.1029/2006GL029175.

Schwager, M., 2000: Ice core analysis on the spatial and temporal variability of temperature and precipitation during the late Holocene in North Greenland, Reports on Polar Research, 362: Alfred Wegener Institute for Polar and Marine Research, Bremerhaven, Germany.

Tibaldi, S. and Molteni, F., 1990: On the operational predictability of blocking, Tellus series A, 42: 343-365.

For full references please consult:

www.pages-igbp.org/products/newsletter/ref2008_2.html 